\title{
TRÁMITES Y SERIICIOS EN EL GAD MUNICIPALIDAD DE AMBATO
}

\section{GAD - AMBATO}

El Gobierno Autónomo Descentralizado Municipalidad de Ambato trabaja en procura de mejorar la calidad de vida sus habitantes, planificando, regulando, facilitando la ejecución de servicios que satisfagan a la comunidad.

Para ello una de las actividades fundamentales que desarrolla el GAD Ambateño, es ofrecer una atención oportuna y eficiente a todos los usuarios del Cantón, a través del Balcón de Servicios.

En esta área se realiza varios trámite como: Declaración y pago de patentes municipales, del 1.5 x mil sobre los activos totales, impuestos prediales, traspasos de dominio de bienes, permisos de rótulos, espectáculos públicos, emisión de certificados de bienes raíces, carta de pago de predio de no adeudar, certificados únicos de habilitación, recepción de solicitudes, uso de suelo, permisos de construcción, permisos varios, permisos de medio ambiente, normas particulares (líneas de fábrica) y replanteos, divisiones, tesorería (Recaudación).

Entre los trámites solicitados estan: patentes, aplica sobre las actividades comerciales, industriales y económicas en general, emitido por la autoridad competente, que permite el desempeño de un empleo, el ejercicio de una profesión o el disfrute de un privilegio; avalúo, estimación del valor o importe de una cosa o valor comercial de un inmueble reflejado en cifras monetarias por medio de un dictamen técnico imparcial; divisiones, partición, separación, reparto, la división se refiere particularmente a la partición de la herencia entre los coherederos, a la del capital social entre los socios; traspaso de dominio, transmisión de la propiedad o de la posesión; permiso, licencia, autorización o consentimiento para hacer; aprobación de planos, aceptación, conformidad, asentimiento, calificación de conveniente o acertado de los planos; solicitud, petición que se realiza a la autoridad; certificado, instrumento por el cual se asegura la verdad de alguna cosa, bajo la fe y palabra del funcionario que lo autoriza con la firma.

El reporte por actividades y el número de trámites ingresados al Balcón de Servicios del GAD Municipalidad de Ambato en el primer trimestre del presente año, se lo puede evidenciar en las siguientes tablas:
Tabla 1. Reporte de Turnos en la Matriz GAD Municipalidad de Ambato Primer trimestre 2014

\begin{tabular}{|c|c|c|c|}
\hline FECHA & $\begin{array}{c}\text { TIrnos } \\
\text { Entregyailos }\end{array}$ & $\begin{array}{l}\text { Turnos } \\
\text { Atendilitos }\end{array}$ & $\begin{array}{l}\text { TIrnos } \\
\text { Alisenters }\end{array}$ \\
\hline AL 31 DE ENERO 2014 & 7725 & 7233 & 492 \\
\hline AL 28 DE FEBRERO 2014 & 9353 & 8889 & 464 \\
\hline AL 31 DE MARZO 2014 & 9733 & 9613 & 120 \\
\hline TOTAL & 26811 & 25735 & 1076 \\
\hline
\end{tabular}

Fuente: GAD Municipalidad de Ambato

Elaboración: OBEST

Tabla 2. Reporte de Trámites en la Matriz GAD Municipalidad de Ambato Primer trimestre 2014

\begin{tabular}{|c|c|c|c|c|c|}
\hline FECHA & Patentes & Trasp|aso & Avaluos & $\begin{array}{l}\text { Solibituiles y } \\
\text { Certifiballos }\end{array}$ & Totilas \\
\hline AL 31 DE ENERO 2014 & 3260 & 1571 & 1590 & 1470 & 7891 \\
\hline AL 28 DE FEBRERO 2014 & 4118 & 1305 & 1635 & 1378 & 8436 \\
\hline AL 31 DE MARZO 2014 & 4997 & 1473 & 1694 & 1244 & 9408 \\
\hline TOTAL & 12375 & 4349 & 4919 & 4092 & 25735 \\
\hline
\end{tabular}

Fuente: GAD Municipalidad de Ambato Elaboración: OBEST

Las actividades que se han realizado en el periodo de enero a junio en la agencia de la Merced son Normas particulares con $47 \%$ respecto a la totalidad de los tramites recibidos, seguido de Replanteos 21\%, Premisos varios 19\%, Aprobación de planos $10 \%$ y Divisiones 3\%.

\section{Figura 1. Reporte de Actividades La Merced enero - junio 2014}

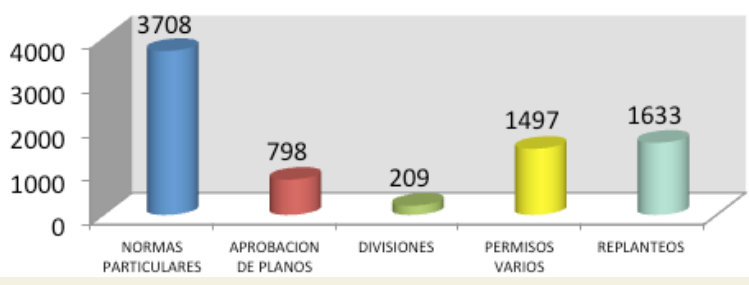

Fuente: GAD Municipalidad de Ambato Elaboración: OBEST. 
En el siguiente grafico se puede observar cómo han ingresado los trámites para la obtención de permisos durante enero a junio de este año, donde se destaca el mes de mayo con 333 trámites siendo el mes con mayor afluencia de ciudadanos para la obtención de permisos y con una caída considerable el mes de junio con 140 trámites es decir una disminución del 58 \% con respecto al mes anterior.

\section{Figura 2. \# de Trámites Ingresados para Permisos Varios enero - junio 2014}

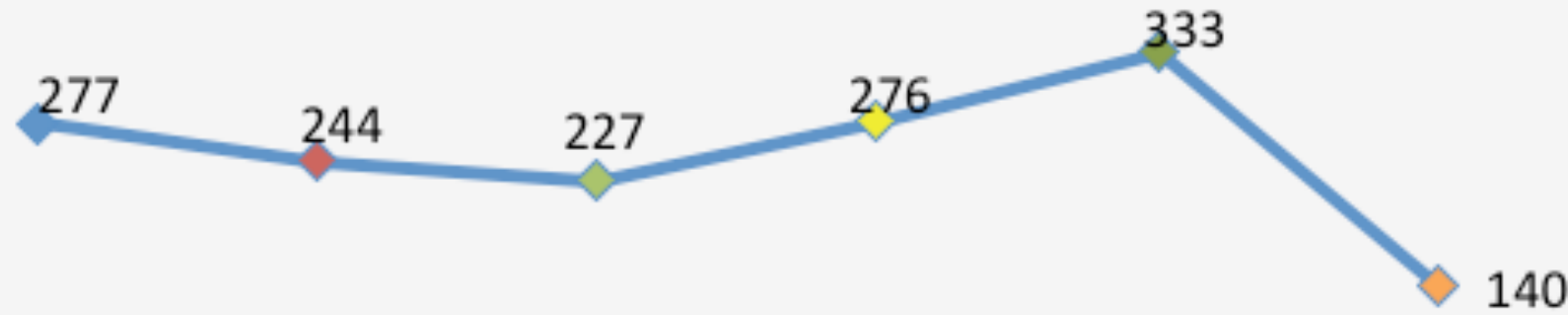

ENERO FEBRERO MARZO ABRIL MAYO JUNIO

Fuente: GAD Municipalidad de Ambato

Elaboración: OBEST.

Los trámites para la presentación de planos en el mes de febrero disminuyó en $11 \%$ con respecto al mes anterior, marzo incrementó un $14 \%$, en abril disminuyó un $1 \%$, mayo incremento un $8 \%$ y en junio disminuyó $64 \%$. Con respecto a los permisos de construcción en el mes de mayo los trámites disminuyen considerablemente en un $57 \%$.

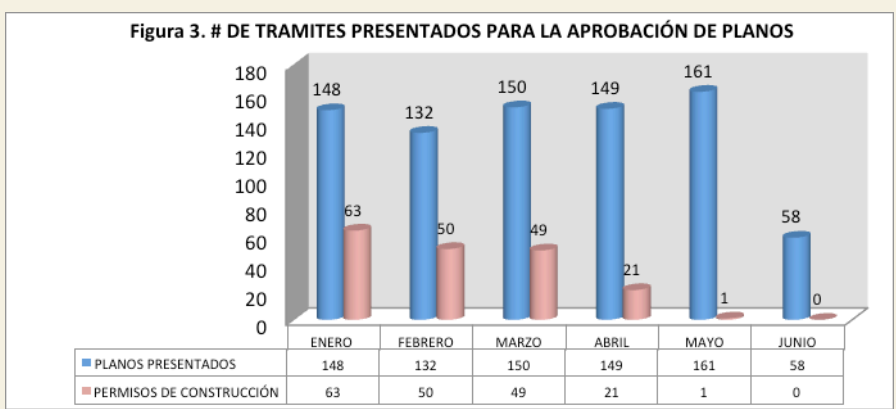

Fuente: GAD Municipalidad de Ambato Elaboración: OBEST
Para realizar todo trámite en el Balcón de Servicios del GAD Municipal, se debe adquirir los formularios correspondientes en las ventanillas de tesorería y acudir a información donde se les entrega formatos para la presentación de solicitudes.

\section{REFERENCIAS}

GAD Municipalidad de Ambato

Observatorio Económico y Social de Tungurahua (OBEST) - Universidad Técnica de Ambato

Colaboradores:

Dr. Ramiro Tite

Ing. Jorge Tamayo 